\title{
HEC MONTRẼAL
}

Institut

d'économie appliquée

The Effect of Adversity on Process Innovations and Managerial Incentives

Benoit DOSTIE

Rajshri JAYARAMAN

Cahier de recherche $n^{0}$ IEA-09-06

Juin 2009 
Institut d'économie appliquée

HEC Montréal

3000 chemin de la Côte-Sainte-Catherine

Montréal (Québec) H3T 2A7

Canada

http://www.hec.ca/iea

iea.info@hec.ca

Copyright (C) 2009 HEC Montréal.

Tous droits réservés pour tous pays. Toute traduction ou toute reproduction sous quelque forme que ce soit est interdite sans l'autorisation expresse de HEC Montréal.

Les textes publiés dans la série des Cahiers de recherche HEC Montréal n'engagent que la responsabilité de leurs auteurs.

ISSN : 0825-8643 


\title{
The Effect of Adversity on Process Innovations
}

\section{and Managerial Incentives*}

\author{
Benoit Dostie ${ }^{\dagger}$ and Rajshri Jayaraman ${ }^{\ddagger}$
}

April 27, 2009

\begin{abstract}
This paper asks whether adversity spurs the introduction of process innovations and increases the use of managerial incentives by firms. Using a large panel data set of workplaces in Canada, our identification strategy relies on exogenous variation in adversity arising from increased border security along the 49th parallel following 9/11. Our longitudinal difference-in-differences estimates indicate that firms responded to adversity by introducing new or improved processes, but did not change their use of managerial incentives. These results suggest that the threat of bankruptcy may provide impetus for improving efficiency. JEL classification: L20, O31, M52, J33
\end{abstract}

${ }^{*}$ We thank Klaus Schmidt for many insightful discussions and seminar participants in Munich and Berlin for useful comments.

${ }^{\dagger}$ Institute of Applied Economics, HEC Montréal, University of Montréal, Montréal (Québec), H3T $2 \mathrm{~A} 7$; IZA, CIRANO and CIRPÉE; benoit.dostie@hec.ca

‡ESMT Berlin, jayaraman@esmt.org 


\section{Introduction}

It is commonly thought that when faced with adversity, characterized by lower profits and the threat of bankruptcy, firms are compelled to innovate in order to reduce costs. The influential work of Porter (1990) arguing that competition compels firms to become more efficient is predicated upon this notion, and the sentiment is widely echoed in business practice. ${ }^{1}$ Of course it is not firms per se, but rather managers working in these firms who typically introduce process innovations. Managerial effort, which is thought to spur innovation, is however non-contractible and once agency considerations are taken into account the effect of adversity on innovation becomes ambiguous.

The reason for this, in the theoretical agency literature, is as follows. ${ }^{2}$ Managers bear a personal cost of bankruptcy - at the very least, they have to find a new job. Hence, when effort is non-contractible, the threat of liquidation induces managers to work harder in order to innovate, reduce costs, and avert bankruptcy.

At the same time, if profits are reduced, a profit maximizing firm may or may not push harder for managers to innovate by offering them higher-powered incentives. Process innovations lower costs and increase profits; However, this increase in profits may be higher in the presence of adversity, or lower in the presence of adversity. If the profitability of process innovation decreases with adversity, a firm faced with adversity will be less inclined to offer its managers incentives in order to spur effort and innovation. If the profitability of process innovation increases with adversity, then adversity will induce a firm to offer its managers more incentives. The net effect of adversity on process innovation therefore depends on whether or not firms increase managerial in-

\footnotetext{
${ }^{1}$ A recent example in the context of the current financial crisis is Janet Rae-Dupree, "It's No Time to Forget About Innovation", New York Times, Nov. 2, 2008.

${ }^{2}$ Our treatment follows Schmidt (1997). Aghion, Dewatripont, and Rey (1999) furnish a model with similar intuition in an economic growth context.
} 
centives, and whether this effect dominates managers' intrinsic motivation to avert bankruptcy. (We elaborate upon this in the next section.)

This ambiguity leaves room for empirical analysis. In this paper we ask two main questions: Do firms faced with adversity (i) introduce new or improved processes and (ii) offer their managers more performance-based incentives? We also, more peripherally, examine managers' effort responses to adversity. We find that the net effect of adversity on introduction of innovation is positive, that is, firms respond to adversity by introducing more new and improved processes. At the same time, firms do not alter their use of performance-based pay to managers, suggesting that this increased use of process innovations is driven by greater managerial effort, motivated by their desire to avert potential bankruptcy. This finding is corroborated by data at the manager level, which suggests that managers working in some firms faced with adversity respond by exerting more effort.

Endogeneity is clearly a challenge in our empirical analysis. It is likely, for example, that a failure to reduce costs through process innovations lowers profits and increases the threat of liquidation. This type of reverse causality would lead to an upward bias in our estimates for the effect of adversity. We deal with potential endogeneity by using a quasi-experiment, which generates exogenous variation in adversity facing firms.

Our data come from the Canadian Workplace and Employee Survey (WES), a rich nationally representative panel of workplace. The periods of observation span September 11, 2001. On that day, the U.S. locked its borders and thereafter, instituted substantially stricter security measures at border crossings. Over eighty percent of the value of Canada's merchandize exports was transported to the U.S. directly across the 49th parallel via truck or rail in that year, and these new border security measures have culminated in considerable 
cost increases for Canadian manufacturers exporting to the U.S. ${ }^{3}$ (We elaborate on this in section 3.)

Exogenous variation from increased border security comes from the fact that firms were only exposed to adversity if they operated in the manufacturing sector and exported their goods to the U.S.. Treatment assignment in this context is determined by whether or not Canadian manufacturers exported goods to the U.S. directly prior to $9 / 11$. We exploit this by using a basic difference-indifferences (double-difference) approach, comparing the changes in innovation as well as the use of managerial incentives between Canadian manufactured goods exporters and non-exporters to the U.S. before and after September, 2001.

In additional robustness checks, we account for unobserved idiosyncratic shocks faced by exporters by estimating a triple-difference, wherein changes in outcomes pertaining to the manufacturing sector are compared with analogous changes pertaining to service sectors, whose exporters are unlikely to have confronted a physical border hinderance but are likely to have faced similar idiosyncratic shocks to exporters in the manufacturing sector. Since (as has been documented in the trade literature) exporters tend to be observationally different from non-exporters, we also conduct our longitudinal double-difference estimation on a matched sample of exporters and non-exporters.

Our analysis is useful for a number of reasons. First, although the use of process innovations is a seemingly natural response to adverse cost shocks, we are (to the best of our knowledge) the first to examine whether this is indeed the case. Second, by examining not only innovation responses, but also responses in terms of the use of managerial incentives and (by exploiting the fact that WES is a matched employer-employee data set) managers' effort, we are able to scrutinize whether the channels through which the theoretical agency literature

\footnotetext{
${ }^{3}$ Calculated from the North American Transportation Statistics Database, Table 6 - 1a, http ://nats.sct.gob.mx/nats/sys/tables.jsp? $i=3 \& i d=27$, accessed Sept. 22, 2008.
} 
suggest cost reductions take place find support in the data. In so doing, we bring together two literatures - one on innovation and the other on managerial incentives - which have been otherwise treated separately in the empirical literature. ${ }^{4}$ Third, our empirical design deals with the potential endogeneity of adversity by using border security measures as a source of exogenous variation in this explanatory variable. Moreover, since WES is longitudinal, we are able to account for time-invariant unobserved heterogeneity in our workplace-level estimations.

Finally, most of the empirical literature to date has concentrated on the effect of competition on managerial incentives or innovation. ${ }^{5}$ Increased competition is, however, only one of many potential sources of adversity, i.e. lower profits and an increased threat of bankruptcy. This paper broadens the scope of the discussion by looking at an alternative source of adversity. At the same time, competition is clearly important, and we account for this by allowing heterogeneous treatment effects, permitting the effect of adversity to vary depending on the degree of (ex-ante) competition faced by the firm.

The paper proceeds as follows. Section 2 describes a theoretical framework within which to analyze our question. Section 3 describes the U.S. border security change which is the source of exogenous variation in adversity. Our empirical strategy and data are described in sections 4 and 5, respectively. Section 6 outlines the empirical model, while section 7 presents our results and section 8 concludes.

\footnotetext{
${ }^{4}$ Vives (2008) in his model explicitly treats them as conceptually interchangeable instruments by which to achieve cost reduction.

${ }^{5}$ Recent contributions include Burgess and Metcalfe (2000), DeFond and Park (1999), Cunat and Guadalupe (2005) for incentives, and (Geroski (1995), Nickell (1996) Blundell, Griffith, and van Reenen (1999), and Aghion, Bloom, Blundell, Griffith, and Howitt (2005) for innovation.
} 


\section{Theoretical Framework}

Our theoretical framework is borrowed from Schmidt (1997), who examines the effect of competition on managerial incentives. Rather than replicate his model here, we provide a verbal description of its salient features, applied to our particular context. Our aim is to provide some intuition for the main result of that model in our particular application.

Consider a risk-neutral firm which is run by a manager. The firm is interested in maximizing net profits, which are equal to gross profits minus the wage offered to the manager. Adversity induces lower gross profits and increases the probability that the firm has to be liquidated. Gross profits are decreasing in production costs, which may be either high or low. The firm has the option of liquidating, in which case gross profits are equal to 0.

Adversity in this context is understood in its broadest sense as an exogenous reduction in profits regardless of production cost regime. Production costs may, however, be influenced by the manager. In particular, managers increase the probability of a production cost reduction by exerting effort and thereby introducing process innovation. The risk-neutral manager is concerned with his wage, net of effort costs. He is protected by limited liability which implies that he must be paid at least at wage of 0 in all states of the world. In addition he incurs a utility loss (for example search costs associated with having to find a new job), in the event that the firm gets liquidated. By assumption liquidation never occurs when the manager was successful in reducing costs. If he was unsuccessful, the probability of liquidation is increasing in adversity.

The agency problem in this context arises from the fact that the firm cannot observe managerial effort. However, the firm does observe the production cost realization (i.e. whether it is in a high or low production cost regime) and so, according to the revelation principle, it should offer wages which are conditional 
on this.

The optimal contract sets wages equal to 0 when the realized production cost is high. When the realized cost is low, the wage leaves a non-negative rent to the manager, so his expected wage may exceed his effort cost. At the same time, disutility associated with a potential liquidation gives an additional incentive to the manager to work harder. This threat of liquidation makes it "cheaper" for firms to induce managerial effort. However, if the probability of liquidation becomes so large that the manager's expected rent shrinks to zero, the firm has to increase the wage to satisfy the manager's participation constraint.

To summarize, adversity has two effects on the probability of a successful production cost reduction (see Schmidt (1997), Proposition 3). First, there is the "threat-of-liquidation" effect. Adversity increases the probability that a firm has to be liquidated if production costs are high. This offers a direct incentive for managers to work harder. At the same time wages in the low production cost regime may have to be increased, in order to compensate the manager for the increased expected utility loss associated with potential liquidation. Both of these work in the same direction, so the threat-of-liquidation effect unambiguously points to an increase in managerial effort.

The second effect is the "value-of-a-cost-reduction" effect. The value-ofa-cost-reduction refers to the difference in profits between the low and high production cost regimes, i.e. how much a cost reduction is worth to the firm. Note that whereas the model assumes that adversity results in reduced profits in both the high and low production cost regimes, it is agnostic about whether this decrease is higher or lower in one regime compared to the other. If the value of a cost reduction is decreasing in adversity, the firm has less of an incentive to offer high-powered incentives to the manager. If this value is increasing in adversity, the firm is more likely offer high-powered incentives to the manager. 
This paper investigates the effect of adversity on three main outcomes: managerial incentives offered by firms to their managers, managerial effort, and process innovation. According to the theory the value of a cost reduction effect determines how firms adjust managerial incentive pay in response to increased adversity. This response may be zero, positive or negative. ${ }^{6}$

Whether or not adversity increases innovation and managerial effort depends, however, on the sum of this value-of-a-cost-reduction effect and the threat-of-liquidation effect. The latter has an unambiguously positive sign. If the former effect is positive or zero, therefore, we expect the aggregate effect of adversity on innovation and managerial effort to be positive. If on the other hand it is negative, then the aggregate effect can be either positive or negative depending on whether this effect of the threat-of-liquidation effect dominates. Empirical work is necessary to find out which effect dominates.

\section{Border security after $9 / 11$}

Our data come from a large panel of Canadian workplaces, spanning September 11, 2001. Canada and the U.S. share a 5,525 mile border. Prior to 9/11, this border was manned by 334 U.S. agents (compared to the 9,000 U.S. agents stationed at the at the 2,062-mile Mexican border) and the expected border crossing delay for transport to the U.S. was 1-2 minutes (Andreas (2005)). On 9/11 the U.S. sealed its borders, effectively imposing an embargo upon itself. This was followed by an extended border clampdown whose immediate consequence was a dramatic slowing of cross-border traffic. In the weeks following 9/11 the media reported border crossing delays from Canada to the U.S. of 1015 hours. (No comparable delays were reported in the press for border crossings

\footnotetext{
${ }^{6}$ Raith (2003) has a similarly ambiguous result arising from the value-of-a-cost-reduction effect in the context of a Salop circular city model with product differentiation.
} 
from the U.S. to Canada.) Under the Patriot Act which was signed into law on October 26, 2001, the number of U.S. agents at the Canadian border trebled, and an additional $\$ 50$ million was allotted towards improving monitoring technology. ${ }^{7}$ Exporters are required to submit cargo manifests at least 1 hour prior to border crossing in order to permit risk assessments, examination rates of trucks crossing the U.S. border from Canada increased from close to zero percent prior to $9 / 11$ to almost 20 percent in 2003, and delays average 1 hour. $^{8}$

Canadian authorities were understandably concerned that the border security issues would prove problematic for Canadian manufacturers. Trade between Canada and the United States constitutes the world's largest bi-lateral trade relationship ever. The U.S. constitutes, by far, Canada's most important international market: $87 \%$ of the value of Canadian merchandize exports (estimated at 240 billion dollars) in 2000 were U.S.-bound, and $40 \%$ of Canada's GDP in that year derived from exports to the U.S.. The vast majority of Canadian merchandize exports to the U.S. are carried via surface modes of transport approximately $60 \%$ (by value) via truck and almost $25 \%$ via rail (Globerman and Storer (2006)).

As the 2001 Budget Plan, presented on December 12, 2001 by the thenfinance minister Paul Martin noted, "A well-functioning Canada-U.S. border is critical to the Canadian economy, and to the manufacturing sector in particular... Since September 11 concern has arisen about predictable and efficient access at the Canada-U.S. border... Unless addressed, unpredictable border delays would hinder production, export growth and investment." (The Budget Plan, Department-of-Finance-Canada (2001), p. 38). On that same day, Canada's Minister of Foreign Affairs, John Manley, and Tom Ridge, the American Homeland Security director, signed the "Smart Border Declaration" (also

\footnotetext{
${ }^{7}$ U.S. Patriot Act, Title IV: Protecting the Border, Section 402.

${ }^{8}$ http : //cbp.gov/linkhandler/cgov/trade/cargo_security/ctpat/ctpat_benefits.ctt/ctpat_benefits.pdf, accessed on Dec. 1, 2008 and Transport-Canada (2005), respectively.
} 
known as the Manley-Ridge accord), which launched 30 major initiatives aimed at strengthening border security, while trying not to discourage trade. ${ }^{9}$

Canadian manufacturers exporting to the U.S. have complained bitterly about the higher costs associated with the new border restrictions. A recent survey of 60 prominent Canadian manufacturers, commissioned by the Conference Board of Canada, points to considerable increases in both direct as well as indirect costs (Goldfarb (2007)). Direct cost increases coincide with higher transportation, freight, insurance, production and compliance costs; and higher indirect costs derive from continued delays, altered delivery patterns (depending on the congestion situation at any given border crossing), driver qualification requirements, and uncertainty regarding the terrorist threats as well as the security policy environment.

It is difficult to attribute a precise cost associated with the new border control measures. However, a recent trucking industry survey suggest that transportrelated components of the costs alone are non-negligible (Transport-Canada (2005)). In particular, the survey estimates that for just the trucking industry, minimum total costs associated with increased border security measures amounts to approximately CAN\$255 million per annum, or a $4 \%$ increase in expenses. $^{10}$

There are three important points to note for the purpose of our empirical design. First, 9/11 was unforseen and this allows us to treat the policy change as exogenous from the point of view of Canadian companies. Second, only

\footnotetext{
${ }^{9}$ Chief among these has been Free and Secure Trade (FAST) launched in December 2002. As the acronym suggests, it is designed to fast-track pre-approved cargo across the border. Another, the Customs-Trade Partnership Against Terrorism (C-TPAT) is a security audit by U.S. customs officials which inspects the entire supply chain and is a pre-requisite to participation in the U.S. FAST. Participation in these and other compliance programmes has, however been meagre: in 2003, only $4 \%$ of shipments were FAST-compliant (OCC (2003)). Moreover, Canadian companies have complained that FAST's efficacy in fast-tracking has been mixed at best (see Goldfarb (2007), p. 15.)

${ }^{10}$ Transport-Canada (2005), p. 37 \& p. ES-4. This comprises CAN\$ 231 mil. for truck delay, 3.4 for driver compliance, 5 for C-TPAT compliance, 2.5 for computer systems, and 14 for administration.
} 
those firms whose business relies on surface goods transportation are subject to costs associated with heightened border security. This means that the potential for treatment in this setting is restricted to the manufacturing sector. Third, Canadian manufacturers who were exporting to the U.S. in 2001 experienced adversity in the sense described in the theoretical framework above: they faced an exogenous reduction in profits as a consequence of heightened border security. And this is true regardless of production cost regime. ${ }^{11}$

\section{Empirical Strategy}

We use a difference-in-differences (double-difference) approach. Our main results compare the changes in two outcomes - the introduction of process innovation and the provision of managerial incentives - between Canadian manufacturing exporters (the treatment group) and manufacturing non-exporters (control group) to the U.S. before and after September, 2001. Export status is measured at the firm level by the proportion of total sales generated from the U.S. market. Treatment assignment in most of our estimates pertains to $25 \%+$ cutoff for this variable. That is, firms are assigned to the treatment group if directly prior to September 2001, $25 \%$ or more of their sales were generated from the U.S. market; they were assigned to the control group otherwise. In our robustness checks, we see whether the main results hold at alternative cutoffs.

Although treatment assignment is based on a predetermined variable, namely export status prior to $9 / 11$, we may still worry that Canadian firms responded to increased border regulation by withdrawing from the U.S. market. If so, this would result in a second-order effect of border regulation on the control group.

\footnotetext{
${ }^{11}$ It is also true regardless of export status following $9 / 11$. This is pretty uncontroversial for those companies exporting goods across the 49th parallel both before and after 9/11: they faced the higher costs alluded to earlier, and profits are decreasing in costs. Of course, some Canadian exporters may have chosen not to export after $9 / 11$ in light of the increased costs of so-doing. Since this option - i.e. not exporting to the U.S. - was also available prior to $9 / 11$, by a revealed preference argument, these manufacturers are also worse off.
} 
In particular, if Canadian exporters responded to increased border regulation by focusing more on the domestic market, this may have resulted in increased competitive pressure faced by non-exporters following $9 / 11$. In that case, our double-difference estimates may be picking up a response to competitive pressure in the control group rather than a response to adversity in our treatment group.

In the event, exports to the U.S. did not wane in the year following 9/11. Figure 1 shows the value of Canadian exports to the U.S. from 1998-2007. The data shown in the figure are aggregate numbers from Trade Canada, pertaining to those 3-digit NAICS manufacturing industries actually covered in our data. As can be seen, the value of exports rose steadily between 2001 and 2002, when security measures were arguably at their most stringent in the direct aftermath of 9/11. In 2003 they dipped but, as can be seen in lower curve in figure 1, this dip was directly associated with the sharp appreciation of the Canadian dollar, starting in Feb, 2003. ${ }^{12}$ This suggests little evidence of externalities associated with reduction in exporters by Canadian manufacturers over our sample period, particularly as the questions pertaining to innovation and managerial incentives following 9/11 are posed specifically for the period between April 1, 2002 and March 31, 2003.

A key identifying assumption in this, as in all difference-in-differences (DD) models, is that outcomes for exporters and non-exporters (the treatment and control group) followed parallel trends. Although this assumption is untestable, we try to get some indication for whether it may be reasonable in our context by calculating a DD estimate for periods prior to $9 / 11$, for the same treatment

\footnotetext{
${ }^{12}$ This appreciation has been attributed by the Bank of Canada to lower inflation and higher interest rates in Canada relative to the U.S. and increased commodity prices
} 


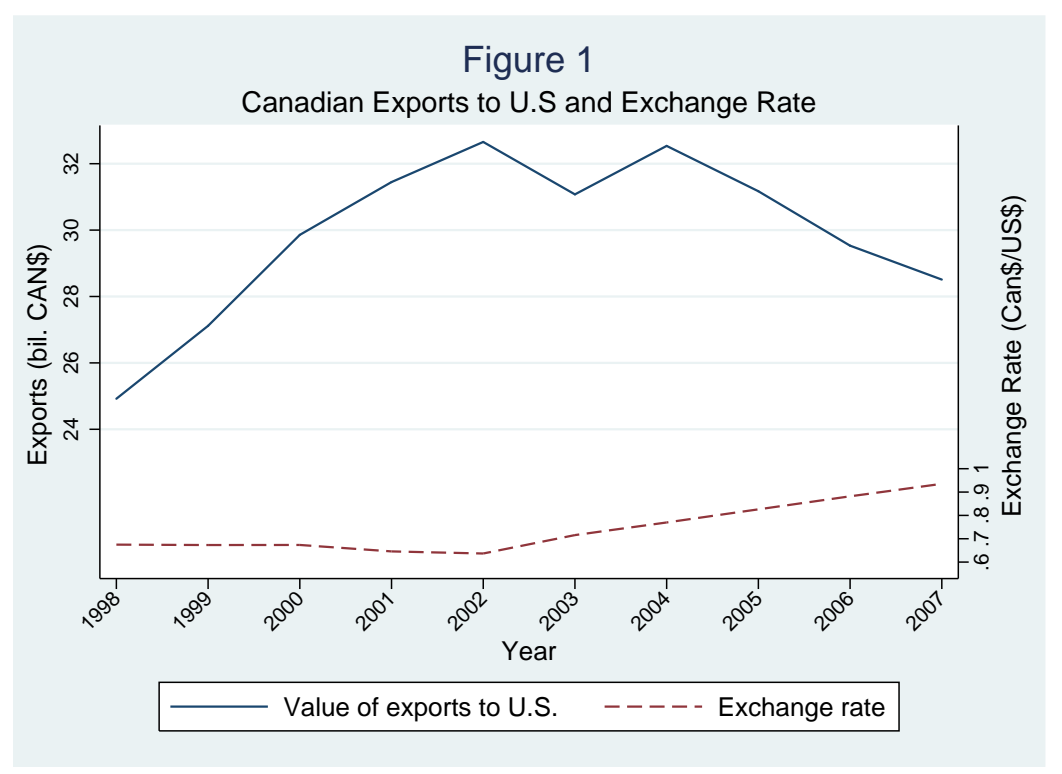

and control group sample used in our main pre/post 9/11 DD analysis. An insignificant DD estimate for this placebo period would be consistent with parallel trends in outcomes prior to treatment.

The Canadian and U.S. economies have historically been very well integrated, which suggests that general economic environment faced by our treatment and control groups are very similar. This is reflected in Figure 2, which shows that growth in both countries have mirrored one another for at least 30 years prior to $9 / 11$, including parallel dips in growth following the dotcom bust. Still, we may worry that Canadian exporters to the U.S. have been confronted with other idiosyncratic shocks since $9 / 11$. We account for this possibility by estimating a triple-difference. This estimate essentially involves comparing changes in innovation and managerial incentives between exporters and non-exporters in the manufacturing sector relative to analogous changes in the 
Figure 2

Economic Growth

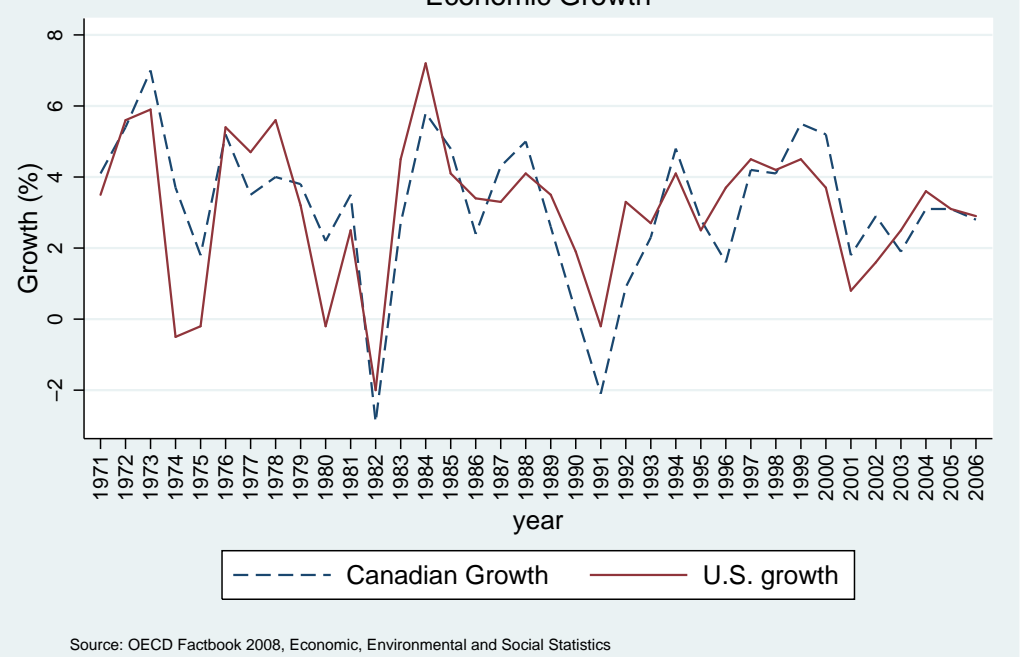

services sector. ${ }^{13}$ The intuition is that whereas exporters in both sectors are likely to be subject to the same types of idiosyncratic shocks, only exporters in the manufacturing sector resort to surface transport across the 49th parallel. This distinction enables us to isolate the effect of adversity associated with border control.

In addition to unobserved idiosyncratic shocks, we know that exporters and non-exporters tend to be different. ${ }^{14}$ Although we control for a large number of observed characteristics, as well as unobserved workplace heterogeneity in our DD estimation, differences between exporters and non-exporters may still be problematic to the extent they are associated with different trends in innovation. We account for this eventuality by conducting our longitudinal DD estimation on a matched sample of exporters (treatment group) and non-exporters (control group).

\footnotetext{
${ }^{13}$ Unfortunately, small sample problems preclude the possibility of using exporters to nonU.S. destinations as a control group.

${ }^{14}$ Bernard, Eaton, Jensen, and Kortum (2003) and Bernard and Jensen (2004) for example, presents recent evidence that plant-level observed heterogeneity affects export status.
} 
We also explore the potential for heterogeneity in treatment effects by examining whether adversity is more likely to spur innovation and managerial incentives among firms which face more intense competition. The idea here is that an increased threat-of-liquidation following from adversity is unlikely to be material for firms which face few competitors. However, this threat is likely to be much more real for a firm operating in a more competitive environment (with smaller profits.) This suggests that we may be more likely to see adversity resulting in increased innovation among firms operating in a more competitive environment.

Finally, we estimate a cross-sectional DD model using our manager-level data to see whether direct proxies of managerial effort corroborate our findings pertaining to innovation, which according to the theory is increasing in managerial effort.

\section{Data}

Our data are from the Workplace and Employee Survey (WES) conducted by Statistics Canada. ${ }^{15}$ The survey is both longitudinal and linked in that it documents the characteristics of workers and workplaces over time. The longitudinal feature allows us to examine within-unit changes in outcomes, thereby correcting for time-invariant workplace unobserved heterogeneity. The linked feature of the data allows us to examine effort responses of managers employed in these workplaces.

Our main results pertain to 2001 and 2003, and additional robustness checks also exploit data from 1999. Survey data were collected from April-July, so our 2001 data correspond to the period just before September 11, and our 2003

\footnotetext{
${ }^{15}$ This is a restricted-access data set available in Statistics Canada Research Data Centers (RDC).
} 
data correspond to the period shortly thereafter. Questions pertaining to our main outcomes of interest refer to the period between April 1, of the previous year and March 31 of the current year in both 2001 and 2003. This size of this window minimizes the possibility that relative changes in outcomes are driven by confounding events. At the same time, the timing of the survey permits 6-18 month lag in firms' process innovation responses to 9/11.

The target population for the workplace component of the survey is defined as the collection of all Canadian establishments which paid employees in March of the year of the survey. The nationally representative sample of approximately 6,000 workplaces per year comes from the "Business Register" of Statistics Canada, which contains information on every business operating in Canada. ${ }^{16}$

Since the potential for treatment in this empirical setting pertains only to those firms whose business relies on surface goods transportation, our core double-difference analysis pertains all to manufacturers in the WES data. These workplaces operate in 4 manufacturing sectors: (i) primary products, comprising wood products, petroleum and coal, non-metallic minerals, and primary metals; (ii) secondary products, comprising chemicals, plastic and rubber, and fabricated metal products; (iii) labor intensive tertiary products, comprising food, beverages and tobacco, textiles and textile products, clothing, leather, and furniture; and (iv) capital intensive tertiary products, comprising printing, machinery, computer and electronics, electric equipment/appliance/component, and transportation equipment.

Our triple-difference estimates compare the double difference estimates in these manufacturing sectors to analogous estimates in service sectors: communication and other utilities, retail trade and consumer service, real estate, rental

\footnotetext{
${ }^{16}$ The survey is therefore nationally representative of Canadian businesses, except for those located in Yukon, the Northwest Territories and Nunavut and firms operating in fisheries, agriculture and cattle farming.
} 
and leasing operations, and information and cultural industries. In our choice of control industries, we try to be as inclusive as possible, while avoiding using industries such as airlines and financial sector services which suffered idiosyncratic shocks during our sample period.

Assignment to treatment, as described in the previous section, is based on the answer to part $(\mathrm{C})$ of the following question in the workplace survey: "Between April 1 [of 2000] and March 31 [of 2001], what percentage of your total sales from all products and services were in each of the following market areas?". The respondent then fills in the percentages associated with: "(A) Local market (same municipality or county), (B) Rest of Canada, (C) U.S.A. and (D) Rest of the world." So, at a $25 \%$ cutoff, a workplace (or the manager therein) is assigned to the treatment group if the answer to (C) is at least $25 \%$ and to the control group otherwise.

Table 1 describes the sample sizes in the treatment and control groups used in most of our estimations. We construct a balanced panel of 1105 workplaces. At the $25 \%$ cutoff, $34 \%$ of these are in the treatment group, and at the $50 \%$ cutoff, this proportion drops to $22 \%$. An additional 204 workplaces were part of the sample in 2001 but are no longer present in 2003. While this attrition rate is small compared to most firm surveys, a key concern remains that if attrition is not random, our balanced sample might be self-selected and the estimated coefficient might not be generalizable.

In order to investigate this concern, we ran regressions for 2001 in which the dependent variable was equal to 1 if the workplace is part of our balanced panel sample and 0 otherwise. Explanatory variables included our dependent variables (innovation and the use of incentives), the number of competitors, percentage of sales deriving from U.S. exports, workplace size, workforce characteristics and investments. It would be especially problematic if, say, innovation was 
found to be closely related to sample selection. In the event, we found that only workplace size had any explanatory power in sample selection, with larger workplaces being more likely to be selected in our sample. This underscores the importance of both controlling for size when estimating treatment effects, and accounting for size in our matched sample estimation.

Table 2 summarizes the mean characteristics disaggregated by treatment and control groups in our sample, according to the $25 \%$ cutoff. The first four rows present time-invariant characteristics pertaining to the manufacturing sector in which the workplace operates. There is a significantly higher proportion of workplaces operating in the primary manufacturing sector, but otherwise, the proportion of firms in each sector is similar in the treatment and control groups. The first three columns correspond to 2001. Workplaces in the treatment group are, on average significantly larger, as reflected in total employment and revenues. They also invest more in software and computer assisted devices (cad), although there is no significant difference in their investment in other technology or machinery (other equip). There is also no significant difference in the number of competitors faced by workplaces in the treatment and control groups in their most important market. ${ }^{17}$ In terms of workforce characteristics, firms in the treatment group have a significantly higher proportion of employees covered by a collective bargaining agreement (CBA), a (marginally) smaller proportion of managers, and an indistinguishable proportion of computer users.

As columns 4-6 indicate, the differences (and similarities) between treatment and control groups, described in the previous paragraph, were very consistent in 2001 and 2003. This is confirmed in the last column, which presents the double-differences corresponding 2001 and 2003: with only one exception, these

\footnotetext{
${ }^{17}$ More specifically, this question asks: "Please indicate how many firms (whether based in Canada or not) offer products/services directly competing with yours in your most important market." The options are $0,1-5,6-20$, and more than 20 . There are no reported monopolists in our sample.
} 
are insignificant.

This suggests that any differences in our outcomes of interest are unlikely to reflect differential changes in characteristics such as workplace size or workforce characteristics, between treatment and control groups. The only exception is investment in computer assisted devices. However, the fact that this double-difference is significantly negative and DD estimates for IT investment in software and other equipment are insignificant is comforting, since it alleviates potential concerns that process innovation may reflect investment in direct compliance responses to new border security measures, which would be consistent with positive and significant DD estimates for IT investment variables. Still, we control for those variables summarized in table 2 which can reasonable be treated as exogenous in our DD framework, and use these variables as a basis of matching in our in our matched sample estimates.

At the workplace level, WES contains uniquely detailed information on two types of outcomes which are important for our purposes. First, we know whether or not workplaces offer their managers a variety of different forms of incentive pay. These include high-powered individual incentive systems (such as bonuses, piece-rate, commissions or merit- or skill-based pay) as well as lower-powered group-based incentives (based on group performance or profit-sharing). Second, in a section entitled "Innovation", the survey asks whether between April 1 of the previous year and March 31 of the current year, the workplace introduced new or improved processes, where new processes are defined explicitly as the "adoption of new methods of goods production", and is distinct from a separate question the introduction of new products.

Our sample of managers contains all the managers who were surveyed as part of the employee-component of WES. Since a different sample of workers is drawn in odd years, we do not have a panel but rather a repeated cross section 
of workers for our sample period. We use two proxies for managerial effort from the employee survey: a dummy variable for whether or not a manager puts in overtime, and the proportion of eligible vacation days the manager actually takes. Our underlying assumption is that managerial effort in increasing in overtime and decreasing in vacation.

In summary, our panel data enable us to compare changes process innovation and managerial incentives within a workplace before and after September, 2001 between exporters and non-exporters in manufacturing, and relative to service sector firms, and allowing for heterogenous treatment effects. It also allows to compare average changes in managerial effort in workplaces exposed to treatment relative to workplaces which were not.

\section{Empirical Model}

We use a longitudinal double-difference model (Imbens and Wooldridge (2009).)

At the workplace level, we estimate the following equation:

$$
y_{j t}=\alpha+\eta D_{t}+\tau w_{j t}+\mathbf{x}_{j t} \gamma+\psi_{j}+\epsilon_{j t}
$$

where $y_{j t}$ is the outcome of interest in workplace $j$ at time $t=2001,2003 . \alpha$ is a constant, and $D_{t}$ is a time dummy equal to 1 in $2003 ; w_{j t}=D_{t} \times T_{j}$, where $T_{j}$ denotes whether $j$ belongs to the treatment group - it a dummy variable equal to 1 if sales to the U.S. of workplace $j$ in 2001 exceed the relevant cutoff ( $25 \%$ in most specifications) and 0 otherwise. In effect, $w_{j t}$ is equal 1 in 2003 for those workplaces which, in 2001, exported goods to the U.S. and were therefore exposed to adversity associated with heightened border security; it is equal to zero otherwise. $\mathbf{x}_{j t}$ is a vector of controls, $\psi_{j}$ is an fixed workplace effect, and $\epsilon_{j t}$ are the idiosyncratic errors. 
Our parameter of interest in equation (1) is $\tau$, which provides an estimate of the effect of adversity on $y_{j t}$. In our main results, $y_{j t}$ measures (i) innovation as a dummy variable equal to one if the workplace introduced new or improved processes and (ii) managerial incentives as a dummy variable equal to 1 if the workplace offered its managers any of the individual-based or group-based alluded to in the previous section. Under the assumption that in the absence of tightened border-security measures introduced following $9 / 11$, outcome changes for exporters would have been the same as that for non-exporters.

Most of our results come from fixed effects (FE) estimation of equation (1) using the the full sample described in table 1. There has been much discussion about the computation of standard errors in difference-in-difference models, so it is worth mentioning how we treat this issue. Most serious criticisms underline the importance of taking into account possible autocorrelation in the error term in models with more than two time periods (Bertrand, Duflo, and Mullainathan (2004)). Since we have only 2 periods, we do not make corrections for autocorrelation in the FE estimates we present in this paper. Donald and Lang (2007) have, however, raised the possibility that residual clustering in the error term could lead to biased tests for statistical significance even in 2-period models. FE estimates with bootstrapped errors, which we also calculated but do not present here, leave the results intact. The standard errors for the DD estimates for innovation fall and those for incentives are virtually unchanged.

In addition to our full sample estimates, we also estimate equation (1) using a matched sample. To construct our matched sample, we estimate a propensity score model in which the probability of being part of the treatment group in 2001 depends on the introduction of innovation, use of managerial incentives, workplace size, workforce characteristics, competition and IT investments. Then, for each workplace in the treatment group, we matched the closest workplace from 
the control group based on the estimated propensity score, and did likewise for workplaces in the control group. We then estimate fixed-effects DD model on various subsamples based how closely we succeeded in matching workplaces in the treatment and control groups.

At the manager level, we estimate the following model:

$$
y_{i j t}=\beta+\eta D_{t}+\delta T_{j}+\tau w_{j t}+\mathbf{x}_{i j t} \gamma+\epsilon_{i j t}
$$

where $y_{i j t}$ is a measure of effort exerted by manager $i$ in workplace $j$ at time $t, \beta$ is an intercept, and $D_{t}, T_{j}$ and $w_{j t}$ are defined as before. Our double difference estimate is the coefficient $\tau$. It measures managers' effort response to adversity. $\mathbf{x}$ denotes a vector of manager characteristics, including age, gender, marital status, race, foreign birth, union status, education, seniority, and workplace characteristics including firm size and sub-industry dummies. $\epsilon$ is an error term.

Since a new sample of workers in any given workplace is chosen every 2 years, we do not observe the same managers before and after the border policy change. We therefore estimate equation (2) using pooled OLS with repeated cross-sections. Note that the sampling procedure precludes us from incorporating workplace fixed effects in the managers-level regression. Since employees are sampled at random, we do not have information on managers for all workplaces present in our previous sample. Moreover, in order to include workplace fixed effects, we would have to observe a manager in the same workplace for both 2001 and 2003. 


\section{Results}

\subsection{Basic Results}

Table 3 presents the percentage of workplaces which introduced process innovations and offered managerial incentives. For each outcome, we present results separately for treatment assignment according to the $25 \%$ cutoff and the $50 \%$ cutoff. The treatment (control) group in each case corresponds to those workplaces which, in 2001, had exports to the U.S. above (below) the cutoff. The top half of the table presents averages and differences between 2001, directly before $9 / 11$, and 2003. The bottom half of the table presents analogous averages and differences for the two periods directly prior to $9 / 11$ (2001 and 1999).

Consider first, the top half of the table. The first column indicates that when treatment assignment is determined at the $25 \%$ cutoff, $50 \%$ of the treatment group introduced a new or improved process in 2001, and this proportion held steady in 2003. In the control group, by contrast, this proportion decreased from $44 \%$ in 2001 to $28 \%$ in 2003 - a significant 16 percentage point reduction depicted in row 3. At the $50 \%$ treatment assignment cutoff in columns 3 and 4, we observe a similar pattern. The proportion of process innovators in the treatment group increased by 7 percentage points (from $43 \%$ to $50 \%$ ) between 2001 and 2003, whereas it decreased by 15 percentage points in the control group (from $45 \%$ to $30 \%$ ).

Columns 5-6 show that the use of managerial incentives decreased slightly in the treatment group from $51 \%$ to $50 \%$ and from $29 \%$ to $22 \%$ in the control group. In contrast to innovation, the latter change was not significant. At the $50 \%$ cutoff, $46 \%$ of workplaces in the treatment group offered managerial incentives in 2001, and this proportion was unchanged in 2003. In the control group, the analogous proportion at the $50 \%$ cutoff declined from $31 \%$ in 2001 to $24 \%$ in 2003 . However, as before, this 7 percentage point decrease is not 
statistically significant.

Row 4 (DD) presents the double-difference estimate one would obtain if equation (1) were estimated using pooled OLS, that is ignoring the workplace fixed effect and treating observations in 2003 as a repeated cross section. The estimates suggest that post-9/11 border security measures resulted in a (significant) 16 percentage point increase in process innovation with the $25 \%$ treatment assignment cutoff. This amount represents a $32 \%$ increase in the introduction of process innovation relative to the proportion of exporting workplaces who introduced new process innovation in 2001. At the $50 \%$ cutoff, this estimate is an even higher 22 percentage points, representing a $51 \%$ increase over the 2001 proportion for the treatment group. The double-difference estimate for managerial incentives is also positive, amounting to 6 percentage points at both the $25 \%$ and $50 \%$ cutoffs. However, this increase is not significantly different from zero.

The bottom half of table 3 conducts an analogous exercise, but comparing average outcomes for a balanced panel of workplaces in 1999 and 2001, instead of 2001 and 2003. (Differences in average outcomes in 2001 in the top and bottom halves of the table are due to sample differences in the balanced 1999-2001 panel and 2001-2003 panel.) Since both these periods of observation precede 9/11, this provides a useful check on our results: if a similar pattern of outcomes emerges during this "placebo" period, our results presented in the top half of the table may simply reflect trends in outcomes particular to Canadian exporters rather than any effects of heightened border security. The results indicate that the pattern is quite different.

Columns 1-2 indicate that innovation fell in both the treatment and control groups at the $25 \%$ cutoff, by 15 and 8 percentage points, respectively. At the $50 \%$ cutoff, in columns $3-4$, the analogous decreases are 20 and 8 percentage 
points. Comparing these averages with those to the top of the table suggests that this downward trend in innovation continued for the control group, but was stymied after $9 / 11$ for the treatment group.

The same general pattern holds in 1999 and 2001 for managerial incentives. The proportion of workplaces offering managerial incentives fell from $60 \%$ to $52 \%(61 \%$ to $49 \%$ ) in the treatment group and from $32 \%$ to $26 \%$ (34\% to $28 \%$ ) in the control group at the 25\% (50\%) cutoff. Between 2001 and 2003, these reductions were of comparable magnitude for the control group, but were much smaller for the treatment group.

The DD estimates in the last row of table 3 are negative and insignificant, in contrast to the positive and, for innovation, significant coefficients for 20012003. This suggests that in the period prior to $9 / 11$, trends in outcomes between exporters and non-exporters were statistically indistinguishable.

Table 4 presents FE estimates of equation (1), with treatment assignment at the $25 \%$ cutoff. The first row presents the double-difference estimate. The DD coefficient in column 1, is significant and of similar magnitude to the OLS estimate in row 4 of table 3 . It suggests that adversity following from more stringent border regulation resulted in a significant 15.7 percentage point increase in process innovation, amounting to a $31.4 \%$ increase relative to the average proportion of process innovators for the treatment group prior to 9/11. Correcting for workplace size and workforce characteristics in column 2 leads to only a small drop in the double-difference point estimate. As columns 3-4 indicate, managerial incentives are unresponsive to adversity: FE DD estimate is not significantly different from zero, whether or not we correct for workplace size and workforce characteristics.

In sum, our basic results suggest that adversity leads workplaces to introduce more process innovations, but has no significant impact on use of managerial 
incentives.

\subsection{Robustness Checks}

One of our mains concern is that the results presented above reflect trends which are particular to exporters rather than any effect of adversity arising from increased border security per se. If this were the case, then we would expect to see a similar pattern of outcomes in time periods unaffected by increased border security. Our first robustness check is therefore to replicate the analysis presented in table 4 for 1999-2001 - the period directly prior to the exogenous security policy change. The results, presented in table 5 reflect a very different pattern: the FE DD estimates in row 1 are negative for both innovation and managerial incentives; They are, moreover, not statistically different from zero. This suggests that prior to $9 / 11$, incentives and innovation were decreasing in a roughly proportional manner for both exporters and non-exporters, which would be consistent with parallel trends in 1999-2001.

Another potential cause of concern is that exporters and non-exporters differ along some observable dimensions. Although we control for these in our basic DD regressions, such differences may still be problematic if they are associated with different trends in outcomes. This concern is tackled in Table 6, which presents FE DD estimates for our propensity score-based matched sample. The sample is constructed by matching every observation from the treatment group to a counterpart in the control group and vice-versa based on values for the propensity score. The difference in propensity scores for every match is then calculated. In columns 1 and 3 (2 and 4 ) of 6 , the sample comprises the $25 \%$ $(50 \%)$ closest matches based on that difference.

The DD estimates presented in column 1 indicate that our basic results go through in this restricted sample with observationally similar exporters and 
non-exporters: Adversity spurs the introduction of process innovations but has no significant effect on the use of managerial incentives. This suggests that our basic results are unlikely to be driven by different trends in outcomes associated with observed differences between exporters and non-exporters.

Table 7 examines how robust our FE DD findings are to sample selection in treatment assignment due to our choice of cutoff, by presenting FE doubledifference estimates analogous to those presented in columns 2 and 5 in row 1 of table 4, using 3 different treatment cutoffs. Each cell in the table corresponds to a FE DD estimate for a different regression.

The dependent variable in column 1 is process innovation. The FE doubledifference estimates in rows 2 and 3 indicate that when treatment assignment is based on a $50 \%$ or $75 \%$ cutoff process innovation remain significant and are even higher than when this cutoff is set at $25 \%$. Although this difference is not statistically significant, to the extent that greater reliance on exports is associated with greater adversity associated with border regulation, this would seem to support our basic result that adversity spurs process innovation.

Column 2 indicates that the same cannot be said for product innovation. Although the sign of the estimates are also positive, they are not statistically significant. This suggests that the forces that drive product and process innovation are very different, and would be consistent with the possibility that product innovation may be a longer-term endeavor and more subject to noise (where luck plays a large role), whereas process innovation can be more easily manipulated as a short-term response to cost shocks. It also lends some credence to the theoretical framework, which assumes that firms respond to adversity through process innovations aimed at reducing production costs.

The dependent variable in column 3 is the same measure of managerial incentives used heretofore. The estimates indicate that our results are robust to 
our choice of cutoff for treatment assignment: the point estimates at the $50 \%$ and $75 \%$ cutoffs are not very different from that in the first row, and remain positive, but statistically insignificant.

It is possible, of course, that firms respond to adversity by changing their use of only high-powered incentives. If so, the fact that our measure of managerial incentives is an aggregate of both high-powered individual incentives (bonuses, piece-rate, commissions or merit- or skill-based pay) and low-powered groupbased incentives may explain the fact that we do not observe a significant effect of adversity on managerial incentives. We explore this possibility in column 4 , by measuring the use of managerial incentives as a dummy variable equal to 1 if the workplace offers its managers high-powered individual based incentives and zero otherwise. As the point estimates indicate, this does not change the results: workplaces do not respond to adversity by resorting to any significant change in their use of solely high-powered managerial incentives either.

Table 8 presents our triple-difference estimates, which measure changes in innovation and managerial incentives between exporters and non-exporters in the manufacturing sectors relative to analogous changes in service sectors. Treatment assignment in this table is set at the $25 \%$ cutoff.

The triple-difference estimates are reported in row 1 . They suggest that our two broad results from the previous section, namely that process innovation increases and managerial incentives do not in response to adversity, are unaltered after we account for potential idiosyncratic shocks among exporters in this manner. At the same time, magnitude of the triple-difference estimate needs to be treated with caution. Those in column 2 and 3 indicate an approximately 35-37 percentage point increase in process innovation, which amounts to an approximately 70 percent increase over the 2001 base level, and this seems to be too large. There are at least three possible reasons for this. One may be that 
changes process innovation are much less ubiquitous in the service sector, so it is easier for the manufacturing sector to cut costs through innovation. Another is that estimates here capture short-run responses followed by a reversion to the negative trend observed in the 1999-2001 data. Finally since service sector tends to be less reliant on exports to the U.S. than the manufacturing sector, they may not feel as much pressure to cut costs as workplaces operating in the manufacturing sector.

\subsection{The role of competition}

Our results so far have suggested that adversity increases innovation but leaves managerial incentives unchanged. This lends support to the idea that firms' response to adversity is driven by the threat of liquidation. Since this threat of liquidation is arguably stronger for firms facing a large number of competitors, we expect the effect of adversity on innovation to be larger for such firms. By contrast, we have no priors regarding how the change in the value of a cost reduction's with respect to adversity, varies at different levels of competition. Hence, it is unclear whether the use of managerial incentives exhibits heterogeneous treatment responses with respect to the number of competitors a firm faces.

In table 9 we allow for heterogenous treatment effects by including interaction terms between $w_{j t}$, the treatment status variable in equation (1), and three dummy variables denoting the number of competitors a workplace faced in 2001, prior to $9 / 11 .^{18}$ The results are consistent with our priors. The DD estimate for process innovation in the first row of column 1, where the treatment cutoff is at $25 \%$, indicates that workplaces with 5 or fewer competitors do not alter process innovation in response to adversity, whereas those which face sufficient competitive pressure - with 6 or more competitors - respond with statistically

\footnotetext{
${ }^{18}$ None of the workplaces in our sample report having 0 competitors.
} 
significant increases in innovation. Although the confidence intervals for the coefficient estimates of each of the interaction terms overlap, our results do suggest that competitive pressure is a necessary condition for the increased use of process innovation.

At a $50 \%$ treatment cutoff, depicted in column 2 , these results are confirmed, if somewhat magnified. For workplaces with 1-5 competitors, the point estimate for innovation is virtually unchanged and not statistically significant. But it is significantly different from zero at the $5 \%$ level (compared to the $10 \%$ level in column 1) and approximately 7 percentage points higher compared to analogous estimates for workplaces with $6-20$ or $20+$ competitors at the $25 \%$ cutoff in column 1 . This suggests that the innovation response observed in the aggregate sample is likely to be driven by those workplaces which operated in a competitive environment and relied heavily on exports to the U.S.

The dependent variable in the last 2 columns of table 9 capture heterogeneous treatment responses in managerial incentives. As before, none of the estimates are significant. This, coupled with the positive effect of adversity on process innovation in competitive environments suggests, suggests that competitive pressure mediates the threat of liquidation effect on introduction of process innovations in these data.

\subsection{Managerial Effort}

The agency model presented in section 2 assumes that process innovation is increasing in managerial effort. Our finding that innovation is increasing in adversity would therefore be consistent with this theoretical framework agency theory if managers do actually exert more effort in response to adversity. In this section, we examine if this is indeed the case. Table 10 presents doubledifference OLS estimates for proxies of managerial effort for the repeated cross 
section of managers in our data for 2001 and 2003. The dependent variable in the first two rows is a dummy variable equal to 1 if the manager worked overtime and 0 otherwise. The dependent variable in columns 3 and 4 is the proportion of eligible vacation days the manager has actually taken.

The sign of DD estimates in row 1 are consistent with managers responding to adversity by exerting more effort. The estimate in column 1 indicates that they are more likely to put in overtime, and that in column 3 indicates that they take less of their eligible vacation time. Both coefficients are, however, statistically insignificant. One possible explanation for this is that managerial response to adversity depends on firm size and failure to account for this results in a downward estimate of the effort response. In particular, managers in smaller firms may be (a) more likely to be residual claimants and (b) more likely to be able to directly influence firm performance and thereby survival. Both of these effects suggest that managers in smaller firms may be exhibit a larger effort response to adversity.

In columns 2 and 4, we allow for heterogenous responses based on the number of employees in the workplace. The results weakly support the possibility that managers in relatively small workplaces may exert greater effort in response to adversity. For overtime, the interaction term is statistically insignificant for mid-sized workplaces and is only marginally statistically significant for workplaces in the largest quartile. The interaction term for the smallest workplaces, however, is significant at the 1 percent level, with a point estimate which is more than twice the magnitude of that for firms in the largest size quartile. With the proportion of vacation days taken, the evidence is somewhat less compelling. The data do suggest that managers in the largest workplaces exhibit no statistically significant effort response to adversity while managers at workplaces in the 25 th to 75 th percentile of the size distribution significantly cut down on the 
number of vacation days to which they are entitled. However, managers in the smallest do not appear to cut down on the proportion of eligible vacation days they take either. ${ }^{19}$

Interestingly, where coefficient estimates for the interaction terms are statistically significant, they are consistent with managers exerting increased effort in response to adversity. This, combined with the fact that the use of process innovations also increases, would be consistent with the model assumptions that process innovation derives from increased managerial effort.

\section{Conclusion}

This paper has exploited a quasi-natural experiment to examine the effect of adversity on process innovation and the use of managerial incentives. In our data, we find that manufacturers respond to adversity by introducing new and improved processes in goods production. However, there is no change in their use of managerial incentives.

In the agency theoretic framework we adopt, process innovation is increasing in managerial effort. Managerial effort is, in turn, driven both by managers' intrinsic incentives to avoid personal costs associated with their employers' bankruptcy, as well as explicit incentive payments offered by firms to their managers. The fact that we observe an innovation response despite observing no change in firms' use of performance-based incentives to managers suggests that the implicit incentive, proffered by the threat of bankruptcy, may provide important impetus to reducing organizational and managerial slack. This intuition is corroborated by results which show that workplaces only respond to adversity by innovating if they face a relatively large number of competitors.

\footnotetext{
${ }^{19}$ One possible reason for this is that in these firms, the management may agree to cut down on eligible vacation days, thereby changing the denominator of the dependent variable in columns 3 and 4 . Increased effort in terms of fewer vacation days taken would be underestimated in this proxy of effort.
} 
It also finds some direct support in our manager-level data, which suggest that managers respond to adversity by exerting more effort.

Our results indicate that the threat of bankruptcy spurs firms to improve efficiency through process innovation. The fact they seem to this so readily begs the question of whether these firms were really operating at minimum cost to begin with, or whether they are characterized by what Leibenstein (1966) famously dubbed as X-inefficiency. If so, our results would be consistent with Leibenstein's contention that X-efficiency may be reduced by "competitive pressure, as well as other motivational factors" (Leibenstein (1966), p.412).

The "motivational factor" for improving efficiency in our context was a negative profit shock associated with increased border regulation. For a much larger shock, however, process innovation may not reduce costs by enough to avert bankruptcy. Conversely, if the motivational factor is weak and does not present firms with a serious threat of bankruptcy, they may not have sufficient incentive to engage in process innovation. In general, our results would be consistent with an inverted U-shaped response of process innovation. ${ }^{20}$

Our results support the popular contention that, when under pressure, firms respond by introducing innovations which reduce costs - that necessity is the mother of process innovation, if you will. An interesting question is where these process innovations come from. Here, our data are opaque. Successful innovation is characterized by a great deal of uncertainty. So, it seems unlikely that these process innovations reflect new inventions on the part of the firm. Rather, these innovations seem more likely to reflect the adoption of extant innovations and this, in turn, presents the intriguing possibility that adversity may spur innovation diffusion.

\footnotetext{
${ }^{20}$ Aghion, Bloom, Blundell, Griffith, and Howitt (2005) present such a relationship between competition and innovation.
} 


\section{References}

Aghion, P., N. Bloom, R. Blundell, R. Griffith, and P. Howitt (2005). Competition and innovation: An inverted-U relationship. The Quarterly Journal of Economics 120(2), 701-728.

Aghion, P., M. Dewatripont, and P. Rey (1999). Competition, financial discipline and growth. Review of Economic Studies 66(4), 825-852.

Andreas, P. (2005, Spring). The mexicanization of the U.S.-Canada border: Asymetric interdependence in a changing security context. International Journal, 449-462.

Bernard, A. B., J. Eaton, J. B. Jensen, and S. Kortum (2003). Plants and productivity in international trade. American Economic Review 93(4), $1268-1290$.

Bernard, A. B. and J. B. Jensen (2004). Why some firms export. The Review of Economics and Statistics 86(2), 561-569.

Bertrand, M., E. Duflo, and S. Mullainathan (2004). How much should we trust differences-in-differences estimates? The Quarterly Journal of Economics 119(1), 249-275.

Blundell, R., R. Griffith, and J. van Reenen (1999). Market share, market value and innovation in a panel of British manufacturing firms. Review of Economic Studies 66(3), 529-54.

Burgess, S. and P. Metcalfe (2000). Incentive pay and product market competition. Technical Report 00/29, CMPO, University of Bristol.

Cunat, V. and M. Guadalupe (2005). How does product market competition shape incentive contracts? Journal of the European Economic Association 3(5), 1058-1082. 
DeFond, M. L. and C. W. Park (1999). The effect of competition on CEO turnover. Journal of Accounting and Economics 27(1), 35-56.

Department-of-Finance-Canada (2001). The budget plan 2001. Technical Report F1-23/2001-3E.

Donald, S. G. and K. Lang (2007). Inference with difference-in-differences and other panel data. The Review of Economics and Statistics 89(2), 221-233.

Geroski, P. (1995). Market Structure, Corporate Performance and Innovative Activity. Oxford: Oxford University Press.

Globerman, S. and P. Storer (2006). The impacts of 9/11 on Canada-U.S. trade. Technical Report 1, Border Policy Research Institute, Western Washington University.

Goldfarb, D. (2007). Reaching a tipping point? Effects of post-9/11 border security on Canada's trade and investment. Technical report, The Conference Board of Canada.

Imbens, G. W. and J. M. Wooldridge (2009). Recent Developments in the Econometrics of Program Evaluation. Journal of Economic Literature 47(1), 5-86.

Leibenstein, H. (1966). Allocative efficiency vs. "X-efficiency". American Economic Review 56(3), 392-415.

Nickell, S. (1996). Competition and corporate performance. Journal of Political Economy 104, 724-746.

OCC (2003). Borders task force, final report. Technical report, Ontario Chamber of Commerce.

Porter, M. E. (1990). The Competitive Advantage of Nations. New York: Free Press. 
Raith, M. (2003). Competition, risk, and managerial incentives. American Economic Review 93(4), 1425-1436.

Schmidt, K. M. (1997). Managerial incentives and product market competition. Review of Economic Studies 64(2), 191-213.

Transport-Canada (2005). The cumulative impact of U.S. import compliance programs at the Canada/U.S. land border on the Canadian trucking industry. Technical report, DAMF Consultants Inc. in association with L-P Tardif \& Associates Inc.

Vives, X. (2008). Innovation and competitive pressure. The Journal of Industrial Economics 56(3), 419-469. 
Table 1: Sample sizes, 2001 and 2003, Manufacturing

\begin{tabular}{|c|c|c|}
\hline \multirow[b]{2}{*}{ Group } & $25 \%$ cutoff & $50 \%$ cutoff \\
\hline & Control Treatment & Control Treatment \\
\hline Number of workplaces & 377 & 863 \\
\hline Total & 1105 & 1105 \\
\hline $\begin{array}{l}\text { Manufacturing include } \\
\text { manufacturing, capital } \\
\text { labor intensive tertiary } \\
\text { to the treatment group } \\
\text { from exports to the U. }\end{array}$ & $\begin{array}{l}\text { primary manufacturin } \\
\text { atensive tertiary manu } \\
\text { nanufacturing. Workp } \\
\text { f the proportion of tot }\end{array}$ & $\begin{array}{l}\text { secondary } \\
\text { acturing and } \\
\text { aces are assigned } \\
\text { sales revenue der }\end{array}$ \\
\hline
\end{tabular}




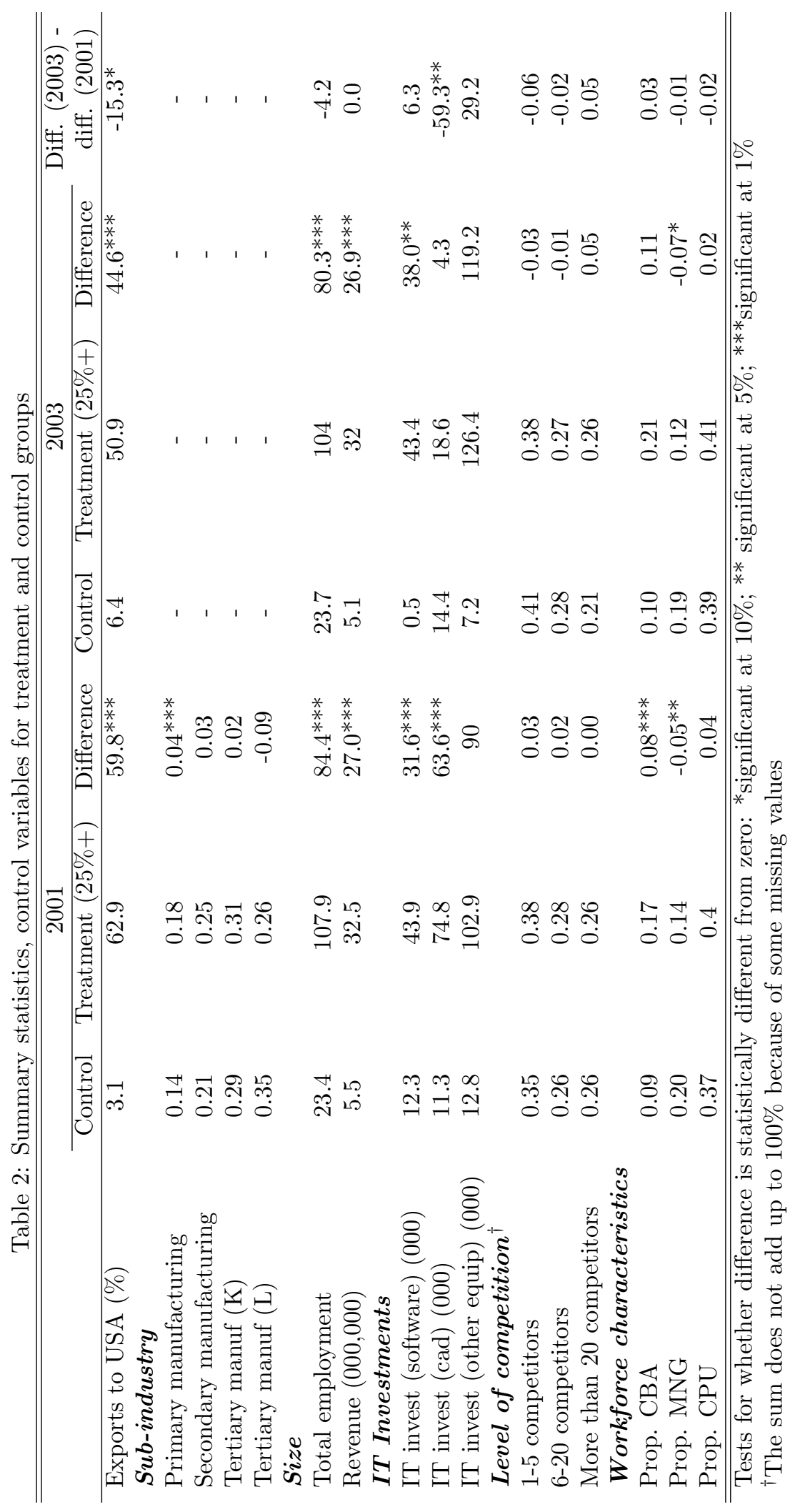




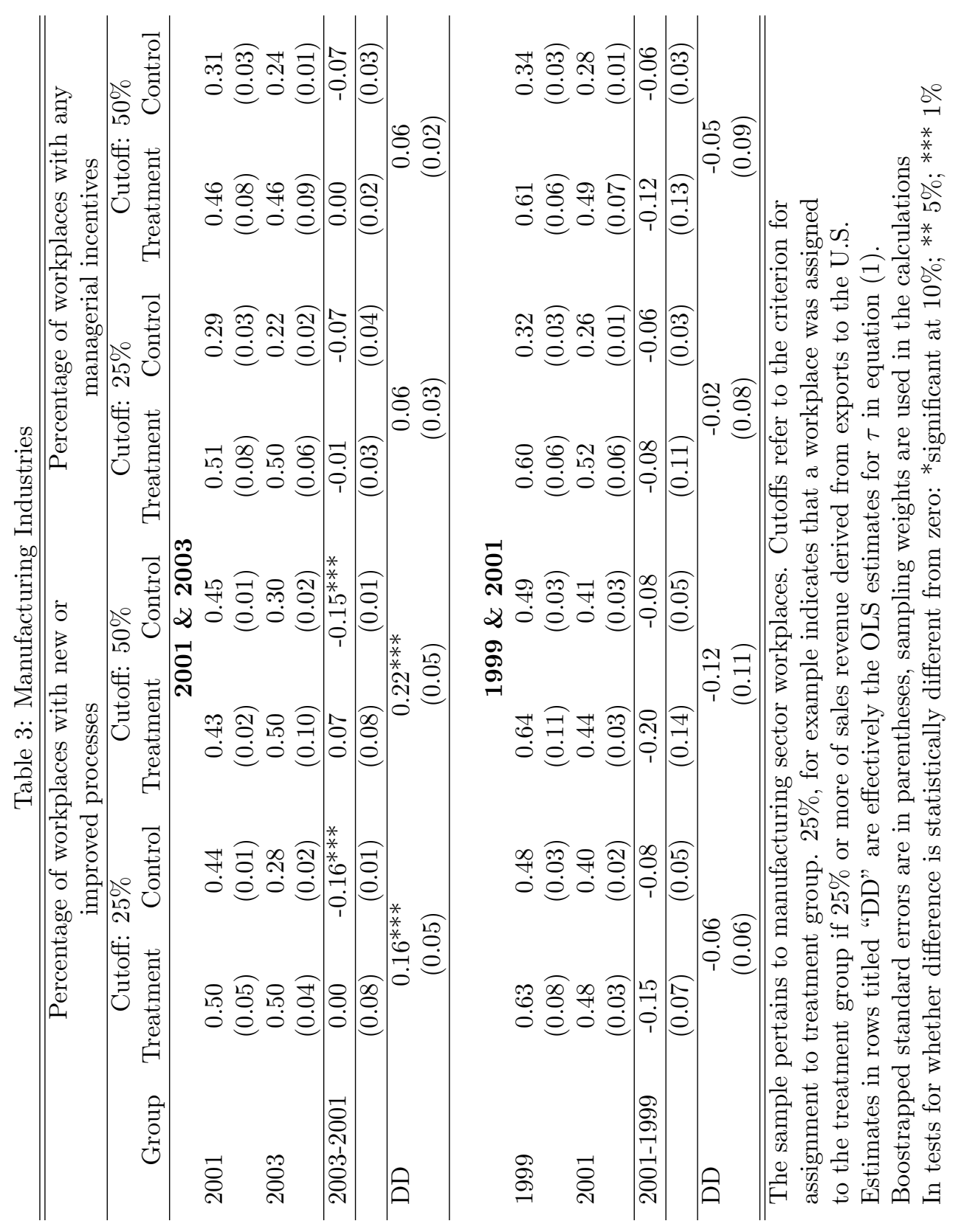


Table 4: Fixed Effects double-difference estimates of the impact of adversity on process innovation and use of incentives

\begin{tabular}{lcccc}
\hline \hline & \multicolumn{2}{c}{ innovation } & \multicolumn{2}{c}{ incentives } \\
\hline Double-diff estimate & $0.157^{* *}$ & $0.148^{* *}$ & 0.054 & 0.056 \\
& $(0.061)$ & $(0.059)$ & $(0.066)$ & $(0.063)$ \\
Year $=2003$ & $-0.153^{* * *}$ & $-0.149^{* * *}$ & $-0.063^{* *}$ & $-0.069^{* * *}$ \\
& $(0.039)$ & $(0.035)$ & $(0.025)$ & $(0.025)$ \\
Constant & $0.446^{* * *}$ & $0.567^{* * *}$ & $0.320^{* * *}$ & $0.147^{* *}$ \\
& $(0.024)$ & $(0.095)$ & $(0.016)$ & $(0.058)$ \\
\hline Controls & $\mathrm{NO}$ & $\mathrm{YES}$ & $\mathrm{NO}$ & $\mathrm{YES}$ \\
Observations & 2210 & 2210 & 2210 & 2210 \\
R-squared & 0.65 & 0.65 & 0.73 & 0.74 \\
\hline \hline
\end{tabular}

Standard errors in parentheses

* significant at $10 \%$; ** significant at 5\%; *** significant at $1 \%$

Assignment to the treatment group is at the $25 \%$ cutoff

Control variables include: firm size dummies, prop. of managers, prop. of computer users and prop. of employees covered by a collective bargaining agreement (CBA)

Table 5: Fixed effects double-difference placebo (1999-2001) estimates of the impact of adversity on process innovation and use of incentives

\begin{tabular}{lcccc}
\hline \hline & \multicolumn{2}{c}{ innovation } & \multicolumn{2}{c}{ incentives } \\
\hline Double-diff estimate & -0.066 & -0.069 & -0.022 & -0.027 \\
& $(0.061)$ & $(0.061)$ & $(0.075)$ & $(0.067)$ \\
Year $=2001$ & $-0.074^{* *}$ & $-0.074^{* *}$ & $-0.062^{*}$ & $-0.049^{* *}$ \\
& $(0.031)$ & $(0.032)$ & $(0.036)$ & $(0.022)$ \\
Constant & $0.501^{* * *}$ & $0.473^{* * *}$ & $0.365^{* * *}$ & $0.278^{* * *}$ \\
& $(0.020)$ & $(0.051)$ & $(0.022)$ & $(0.051)$ \\
\hline Controls & $\mathrm{NO}$ & YES & $\mathrm{NO}$ & YES \\
Observations & 2224 & 2224 & 2224 & 2224 \\
R-squared & 0.66 & 0.66 & 0.74 & 0.76 \\
\hline \hline
\end{tabular}

Standard errors in parentheses

* significant at $10 \%$; ** significant at $5 \%$; *** significant at $1 \%$

Assignment to the treatment group is at the $25 \%$ cutoff

"Controls" refer to those variables mentioned in table 4 
Table 6: Fixed effects double-difference estimates of the impact of adversity on process innovation and use of incentives on matched samples

\begin{tabular}{lcccc}
\hline \hline & \multicolumn{2}{c}{ innovation } & \multicolumn{2}{c}{ incentives } \\
& 25 & 50 & 25 & 50 \\
\hline Double-diff estimate & $0.268^{* *}$ & $0.213^{* *}$ & 0.183 & -0.001 \\
& $(0.115)$ & $(0.098)$ & $(0.111)$ & $(0.104)$ \\
Year $=2003$ & $-0.160^{*}$ & $-0.153^{* *}$ & -0.020 & -0.035 \\
& $(0.090)$ & $(0.076)$ & $(0.063)$ & $(0.058)$ \\
Constant & $0.440^{* * *}$ & $0.439^{* * *}$ & $0.286^{* * *}$ & $0.371^{* * *}$ \\
& $(0.043)$ & $(0.035)$ & $(0.037)$ & $(0.035)$ \\
\hline Observations & 380 & 752 & 380 & 752 \\
R-squared & 0.70 & 0.68 & 0.72 & 0.67 \\
\hline \hline
\end{tabular}

Estimates are for a propensity-score matched sample of workplaces

in the treatment and control groups, where initial treatment assignment

is based on the $25 \%$ export cutoff. The numbers in the column

headings refer to the $25 \%$ closest matches and $50 \%$ closest matches.

with sample sizes increasing accordingly.

Standard errors in parentheses

${ }^{*}$ significant at $10 \% ;{ }^{* *}$ significant at $5 \% ; * * *$ significant at $1 \%$

Table 7: Summary table of FE double-difference estimates

\begin{tabular}{lcccc}
\hline \hline Export cutoff & \multicolumn{2}{c}{ Innovation } & \multicolumn{2}{c}{ Incentives } \\
& process & product & any & high-powered \\
\hline $25 \%+$ & $0.148^{* *}$ & 0.062 & 0.056 & 0.084 \\
$50 \%+$ & $0.205^{* * *}$ & 0.052 & 0.075 & 0.056 \\
$75 \%+$ & $0.185^{* *}$ & 0.110 & 0.041 & -0.057 \\
\hline \hline
\end{tabular}

Each cell in this table refers to the FE double difference

estimate corresponding to a different regression, in which the assignment to treatment is reflected by the cutoff in the first column

and the dependent variable is indicated in the column heading

In each case, all the controls mentioned in table 4 are included 
Table 8: Fixed Effects triple-difference estimates of the impact of adversity on process innovation and use of incentives

\begin{tabular}{lcccc}
\hline \hline & \multicolumn{2}{c}{ innovation } & \multicolumn{2}{c}{ incentives } \\
\hline Triple-diff estimate & $0.366^{* * *}$ & $0.352^{* * *}$ & -0.031 & -0.038 \\
Year $=2003$ & $(0.122)$ & $(0.122)$ & $(0.144)$ & $(0.143)$ \\
& 0.022 & 0.022 & -0.036 & -0.031 \\
Year $=2003 *$ Treat & $(0.036)$ & $(0.035)$ & $(0.027)$ & $(0.026)$ \\
& $-0.201^{*}$ & $-0.192^{*}$ & 0.090 & 0.092 \\
Year $=2003 *$ Manuf. & $(0.105)$ & $(0.105)$ & $(0.128)$ & $(0.127)$ \\
& $-0.182^{* * *}$ & $-0.179^{* * *}$ & -0.033 & -0.038 \\
Constant & $(0.053)$ & $(0.052)$ & $(0.039)$ & $(0.038)$ \\
& $0.257^{* * *}$ & $0.283^{* * *}$ & $0.269^{* * *}$ & $0.235^{* * *}$ \\
Controls & $(0.022)$ & $(0.084)$ & $(0.018)$ & $(0.053)$ \\
Observations & $\mathrm{NO}$ & $\mathrm{YES}$ & $\mathrm{NO}$ & YES \\
R-squared & 4632 & 4632 & 4632 & 4632 \\
\hline \hline
\end{tabular}

The comparison group in these triple difference estimates are workplaces in the service sector.

Standard errors in parentheses

* significant at $10 \%$;* significant at $5 \%$; ** significant at $1 \%$

Assignment to the treatment group is at the $25 \%$ cutoff

"Controls" refer to those variables mentioned in table 4

Table 9: Heterogeneous response to adversity: effect of competition

\begin{tabular}{lcccc}
\hline \hline \multirow{2}{*}{ Cutoff for exports to USA } & $25 \%+$ & $50 \%+$ & $25 \%+$ & $50 \%+$ \\
\hline DD(1-5 competitors) & 0.110 & 0.151 & 0.100 & 0.059 \\
& $(0.094)$ & $(0.128)$ & $(0.093)$ & $(0.104)$ \\
DD(6-20 competitors) & $0.179^{*}$ & $0.256^{* *}$ & -0.075 & 0.004 \\
& $(0.098)$ & $(0.116)$ & $(0.139)$ & $(0.170)$ \\
DD(more than 20 comp.) & $0.159^{*}$ & $0.232^{* *}$ & 0.075 & 0.109 \\
& $(0.083)$ & $(0.114)$ & $(0.081)$ & $(0.084)$ \\
Year $=2003$ & $-0.147^{* * *}$ & $-0.143^{* * *}$ & $-0.066^{* * *}$ & $-0.065^{* * *}$ \\
& $(0.035)$ & $(0.033)$ & $(0.025)$ & $(0.024)$ \\
Constant & $0.570^{* * *}$ & $0.572^{* * *}$ & $0.143^{* *}$ & $0.146^{* *}$ \\
& $(0.096)$ & $(0.096)$ & $(0.059)$ & $(0.059)$ \\
\hline Observations & 2210 & 2210 & 2210 & 2210 \\
R-squared & 0.65 & 0.66 & 0.74 & 0.74 \\
\hline \hline
\end{tabular}

Regressions are estimated using fixed effects.

Standard errors in parentheses

* significant at $10 \%$; ** significant at $5 \%$; *** significant at $1 \%$

Assignment to the treatment group is at the $25 \%$ cutoff

"Controls" refer to those variables mentioned in table 4 
Table 10: Managerial Effort response: OLS Double-difference estimates

\begin{tabular}{lcccc}
\hline \hline \multirow{2}{*}{ DD } & paid or unpaid overtime & prop. of vacation taken \\
\cline { 2 - 5 } & 0.125 & & -0.109 & \\
DD $(\mathrm{emp}<\mathrm{p} 25)$ & $(0.131)$ & $(0.091)$ & 0.020 \\
& & $0.421^{* * *}$ & & $(0.143)$ \\
DD $(\mathrm{p} 25 \leq \mathrm{emp} \leq \mathrm{p} 75)$ & & $(0.137)$ & & $-0.218^{* *}$ \\
& & 0.070 & & $(0.108)$ \\
DD $(\mathrm{emp}>\mathrm{p} 75)$ & $(0.191)$ & & 0.039 \\
& & $0.174^{*}$ & & $(0.101)$ \\
Year $=2003$ & -0.062 & -0.061 & 0.020 & 0.021 \\
& $(0.055)$ & $(0.055)$ & $(0.046)$ & $(0.046)$ \\
Treatment group & 0.055 & 0.056 & 0.096 & 0.101 \\
& $(0.087)$ & $(0.088)$ & $(0.070)$ & $(0.070)$ \\
Constant & -0.326 & -0.329 & $0.939^{* *}$ & $0.916^{* *}$ \\
& $(0.417)$ & $(0.417)$ & $(0.391)$ & $(0.396)$ \\
\hline Controls & YES & YES & YES & YES \\
Observations & 899 & 899 & 868 & 868 \\
R-squared & 0.19 & 0.19 & 0.06 & 0.06 \\
\hline \hline
\end{tabular}

Robust standard errors in parentheses

* significant at $10 \% ; * *$ significant at $5 \%$; *** significant at $1 \%$

Assignment to the treatment group is at the $25 \%$ cutoff p25 and p75 refer to the 25th and 75th percentile in the number of employees at the workplace (emp) distribution

Controls include age quadratic, women, married, ethnicity, born outside Can, CBA, education, seniority, seniority squared, firm size and sub-industry 